\title{
External Technology Acquisition of SMEs in the Machinery Industry of Bangalore
}

\author{
M.H. Bala Subrahmanya ${ }^{*}$, Zeeshan Hussain, Ashwin Chand M.**
}

Submitted: Feb. 06, 2014; Accepted: April 17, 2014; Published Online: May 01, 2014

\begin{abstract}
This paper is an attempt to understand the external technology acquisition (ETA) process of the machinery SME sector in Bangalore city, India. With the onset of economic liberalization, Bangalore based machinery SMEs have significantly shifted their ETAs from India to abroad, particularly Germany and Japan, among others. The primary objective of ETAs is to enhance their competitiveness by means of improving product quality and productivity as well as meeting customer demand. Replacing outdated machinery or overcoming technological obsolescence is a primary objective of only a few. As a result, majority of the SMEs has gone for multiple ETAs since their inception and we found a statistically significant positive correlation between firm age and number of ETAs. The present study has made two empirical contributions: (i) We have thrown light on the core technology up-gradation issue How do SMEs approach the problem of external technology acquisition in the current globalization era? (ii) We are able to identify and develop a map of ETA process based on the "learning and experiences" of these SMEs.
\end{abstract}

Keywords SMEs, external technology acquisition, technology acquisition process mapping, Bangalore, machinery industry, India

\section{Introduction}

Technological obsolescence is a major problem afflicting the small \& medium enterprises (SME) sector in developing countries, like India. The Indian Prime Minister's Task Force on Micro, Small and Medium Enterprises

\footnotetext{
* Chairman \& Professor, Department of Management Studies, Indian Institute of Science, Banglaore, India; bala@mgmt.iisc.ernet.in

${ }^{* *}$ Project Assistant, Department of Management Studies, Indian Institute of Science, Bangalore, India
} 
(MSMEs) has identified low technology, generally used by the MSME sector, as a major cause for poor competitiveness of the sector (Ministry of MSMEs, 2012a). To overcome this problem, Indian Policy Makers have extended support to SMEs for External Technology Acquisition (hereafter ETA) to achieve technology up-gradation and modernization through policy initiatives and financial incentives (Ministry of MSMEs, 2012b). How have SMEs responded to policy support and gone for technology up-gradation and modernization? What have they learnt in the process? Is there any pattern in the process of ETAs achieved by SMEs? If yes, can it be generalized so that SMEs which approach ETAs without prior experience will stand to gain? These are the relevant issues that need to be understood in the context of ETAs achieved by SMEs.

This study proposes to examine the process of ETAs achieved by SMEs in the engineering industry of Bangalore. Bangalore occupies a unique position in India as it is known internationally as India's "high-tech city" (Department of Industries and Commerce, website, 2012). Bangalore is considered one of the 46 "global hubs of technological innovation" (UNDP, 2001) and it is one of the globally known technology cities in the world (Rogers, et al, 2001). Bangalore has a relatively high concentration of engineering industries and SMEs, historically in India (Bala Subrahmanya, et al, 2002). Bangalore has many nationally renowned educational and research institutions and R\&D centres of MNCs (Bala Subrahmanya, 2005a; DST, 2010). It has a significantly high presence of technically qualified entrepreneurs in SMEs, particularly in engineering industries (Bala Subrahmanya, 2005b).

In addition, Bangalore is home for several SME supporting institutions for technology transfer such as Karnataka Council for Technology Upgradation (KCTU), Technology Resource Centre (TRC), regional branch of National Research Development Corporation (NRDC), Central Manufacturing Technology Institute (CMTI), Bangalore and technology financing institutions (through exclusive schemes) such as Karnataka State Financial Corporation (KSFC), Karnataka branch of Small Industries Development Bank of India (SIDBI), and State Bank of India (SBI). Bangalore has active SME associations under the umbrella of Karnataka Small Scale Industries Association (KASSIA), which is considered an apex association of SMEs in the state. KASSIA in turn has 47 sector specific Bangalore based SME 
associations as its members (KASSIA, 2012). These associations enable periodic interaction and exchange of information among its members, among others. All these represent different components of the "ecosystem" of Bangalore for small firms which would have contributed to the "technologically vibrant environment" for SMEs in the city. As a result, SMEs in the city might be better exposed and have easier access to modern technologies. Further, SMEs of the city may be "better learners" with respect to acquisition of technologies. Considering all this, looking at the ETAs achieved by SMEs in Bangalore city in the context of engineering industry seems appropriate. We have looked at the ETAs achieved by 68 engineering SMEs since their inception till 2010.

\section{Core Issues of ETA}

Technology is a major determinant of a firm's survival and growth in business. Many firms which have failed to cope with changing technology trends have gone out of business. To cope with dynamic technology trends, either a firm has to engage itself in technology development or acquire technologies from external sources from time to time. In general, SMEs are identified with resource constraints, the most noteworthy being lack of inhouse technological competence. Therefore, they can hardly attempt to develop technology internally.

According to Noori (1990) high costs of conducting internal R\&D have resulted in a growing trend toward acquiring new technologies by some other means. In general it can be argued that the decision to purchase a fully functioning and a widely used product technology from another firm could result in superior product quality (Lanctot and Swan, 2000). The principal advantage of external technology acquisition as a key growth strategy is that it can reduce the time required from formulation of an original technical concept to its ultimate commercialization (Robertson, 1993). This assumes significance especially when technology changes occur at a rapid rate.

With rapidly changing and complex technology, external technology acquisition has become an important component of a firm's technology strategy and supports its competitive advantage and positioning (Zahra, et al, 1994). Limited resources, expertise and time are the factors that push many 
firms to acquire technology from a source external to the firm rather than developing it in-house (Stock and Tatikonda, 2004). By acquiring external technologies, firms could gain several benefits such as decreasing development time and risks (Tsai and Wang, 2008). But according to Koc and Ceylan (2007) most companies in developing countries prefer external sourcing of technologies because most of the technologies they use are outside or beyond their resource capabilities.

There are various channels through which SMEs can acquire external technologies. Some of them are as follows (Daim and Kocaogh, 2008):

- Sponsoring a research in a University

- Supporting employees' education and thereby assess candidate technologies

- Make use of an external R\&D centre

- Employ consultants to help them assess the new technologies available to them in the market

- Firms may go for licensing, which has been listed as one of the widely utilized methods of technology acquisition

- Technical meeting, technical journals and trade shows are used to assess technologies

- Purchasing existing technology either through the vendor/supplier or from any commercial channel.

Identifying an appropriate channel and acquiring technology through a particular channel is a challenge. As a pre-requisite, a SME has to be clear about its technology needs before scouting for a channel. Once the technology networks are identified, then it is important to understand the varieties of technologies available and the one most suitable for a particular SME (Lanctot and Swan, 2000). While the transfer of machinery and equipment is, in most cases, a necessary first step, what is more important is the transfer of information and skills to the employees of the technology receiving firm, which constitutes the second step. The second step is more important because if the technology acquiring firm has to effectively use the transferred technology, acquisition of necessary information and skills related to the use of the new technology is essential and crucial (Bischoff, 2001).

In the light of the above discussion, it is important to ascertain the broad characteristics of technology transfer mechanism or ETA achieved by SMEs, 
and examine whether there is any pattern that SMEs follow in the process of achieving ETA. Further, it is appropriate to know whether SMEs learn the art of ETAs when they undergo repeated ETAs. While identifying a pattern would help SMEs in general for future ETAs, learning the art of ETAs would enable them to achieve savings in terms of time, efforts and cost. The objectives of the study are set in this context.

\section{Objectives, Scope and Methodology}

The two core objectives of the study are as follows:

- To understand the broad characteristics of ETAs achieved by SMEs in India in the era of globalization in terms of technology shift, source of technology, time taken for ETAs and the ETA process.

- To examine the factors which influenced the technology shift, source of technology, time taken for ETAs and the ETA process.

The above objectives are studied with reference to the manufacturing sector SMEs in Bangalore city in India. SMEs in the present study are defined, following the MSMED Act, 2006 of Government of India, as manufacturing enterprises whose individual investments in plant \& machinery did not exceed Rs.100 million as of 2010/11 (Ministry of MSMEs, 2012b). The focus of the study is confined to those SMEs, which have acquired external technologies through either government promoted institutional network or private sources or MNCs from a foreign country since 1991. We consider 1991 as the starting point for the study because 1991 is a land mark year for Indian economy as it launched the broad based economic reforms in that year, which signified the opening up of Indian economy to internal as well as external competition.

An important dimension of these economic reforms is the removal of controls and regulations for the inflow of foreign capital as well as foreign technology (Bala Subrahmanya, 2004). This would have prompted as well as facilitated many Indian SMEs to upgrade their technologies through external technology acquisition to enhance their competitiveness for survival and growth in the emerging globally competitive environment since 1991. In the present study, external technology acquisition or technology transfer refers to 
acquisition of new plant \& machinery and related know-how by a SME from external sources, with or without the help of government promoted SME support organizations, from other enterprises or technology suppliers or R\&D institutions or Universities.

To select an industry for the study, first of all, we developed a database of Bangalore SMEs, which have acquired external technologies since 1991 by approaching all central government promoted institutions, Karnataka government promoted institutions and SME associations. We approached (i) Directorate of Industries \& Commerce, Government of Karnataka; (ii) Karnataka Council for Technology Up-gradation (KCTU), Bangalore; (iii) Technology Resource Centre (TRC), Bangalore; (iv) National Research Development Corporation (NRDC), Bangalore; (v) Central Manufacturing Technology Institute (CMTI), Bangalore, (vi) Small Industries Development Bank of India (SIDBI), Bangalore; (vii) State Bank of India (SBI), Local Head Office, Bangalore; (viii) Karnataka State Financial Corporation (KSFC), Bangalore; (ix) India SME Technology Services Ltd., New Delhi, (x) Karnataka Small Scale Industries Association (KASSIA), Bangalore, and (xi) Peenya Industries Association (PIA), Bangalore. However we got database of a total of 457 Bangalore SMEs which have acquired external technologies since 1991, only from KCTU, NRDC, SIDBI, SBI and KSFC. We tabulated these data industry-wise according to National Industrial Classification (NIC), 2008, after removing multiple entries of enterprises. We selected manufacture of machinery (not elsewhere classified) industry for our study as it contained a maximum of 126 SMEs out of a total of 245 SMEs.

By making use of a semi-structured questionnaire we gathered primary data from a total of 68 machine-manufacturing SMEs located in Bangalore, during August-December 2011. The semi-structured questionnaire comprised a total of 71 questions covering qualitative as well as quantitative variables, under five sections as follows: (i) Unit profile, (ii) Technology profile, (iii) Technology transfer profile, (iv) Innovation profile, and (v) Achievement profile. 


\section{Characteristics of ETA}

At the outset, it is important to describe the general profile of 68 surveyed SMEs. All the 68 SMEs have emerged as start-ups and their founder entrepreneurs are first-generation entrepreneurs. The oldest SME was established in 1964 whereas the youngest in 2010. These are proprietorship (60\%) or partnership (40\%) concerns. Most of them are functioning for more than a decade and the age of entrepreneurs varied from late 20 s to early $80 \mathrm{~s}$. More than half of them are technical graduates and another $1 / 3$ is technical diploma holders. Thus entrepreneurship has a considerable presence of technical education background. Majority SMEs (88\%) are primarily machine component manufacturers whereas the remaining (12\%) SMEs are machine product manufacturers. Further, majority SMEs (nearly 90\%) have established ICT network in the form of either e-mail or both e-mail and web page, and both are used for commercial communication and interactions.

At the outset, it is important to understand why Bangalore SMEs preferred ETAs to in-house development of better technologies, particularly CNC machines. Though a substantial majority of the 68 SMEs had technically qualified CEOs, these SMEs did not have the technically capable human resources and financial resources to develop the needed $\mathrm{CNC}$ technology on their own nor did they desire to have technical collaboration with external institutions (including government agencies and research institutes/ universities) since that would consume more time and capital. That is why, these SMEs opted for buying readily-available, ready-made machines rather than making those machines themselves. They found it economical time-wise, effort-wise and cost-wise.

With the above backdrop, it is important to understand the present technology status and the change occurred with respect to the origin of SMEs. That is, how has the nature of technology changed for 68 SMEs from the past to the present is an important dimension of technology. Table 1 presents details on how the technology (plant \& machinery) of SMEs has changed over a period of time from their inception, irrespective of their period of origin, to the present day. It is interesting to note that as many as 33 of the SMEs had conventional lathes whereas only 13 of them had CNC machines as their main plant $\&$ machinery at the time of inception and the rest had grinding \& milling (5), horizontal boring (2), drilling (2), single spindle (SS) 
automation (2) and other types of machinery(11). But in 2011 when we carried out the survey, 54 of the 68 SMEs (almost 80\%) had acquired various kinds of CNC machines.

Twenty six of the 33 SMEs which had conventional lathes shifted to CNC machines whereas only 5 SMEs which had conventional lathes continued to have conventional lathes as their main plant $\&$ machinery. One each of those who had conventional lathes shifted to electrical discharge machining and special purpose machine, respectively. Among the remaining SMEs which had other technologies, some of them continued to have the same technology such as drilling, Gear hobbing, horizontal boring, SS automation, and TIG wielding. All the 13 SMEs which started their operations with $\mathrm{CNC}$ machines continued to have $\mathrm{CNC}$ machines even now. Overall, it can be observed that adoption of CNC machines has been the most striking technology upgradation achieved by the SMEs through ETA. In modern CNC systems, end-to-end component design is highly automated using computer-aided design (CAD) and computer-aided manufacturing (CAM) programmes. Accordingly, we found that 49 (about 91\%) of the 54 SMEs (which use CNC machines) have adopted CAD/CAM programs. In the process, these SMEs would have also strengthened their software capability to adequately adapt the new CNC machines to meet their objectives. Given the above, CNC machines can be considered a synergistic target for the machine tool industry in Bangalore.

It is important to note, as stated by the SME entrepreneurs, that technology of CNC machines is fairly matured and over a period of time $\mathrm{CNC}$ machines are applied to more and more machine manufacturing operations. This is also reflected in the technology change achieved by the 68 SMEs covered by the present study (Table 1). Only where the scale of operations is too small to operate and where labour skills are more important, adoption of CNC machines is avoided. Of course, the more dynamic ones, among those who have absorbed better technologies and who would acquire their own technological competence in the process, might think of innovating "newer versions" of these technologies in the future. In the "high-technology ecosystem of Bangalore", this may be a feasible proposition. 
Table 1 Technology Change Achieved through ETA in SMEs

\begin{tabular}{|l|r|r|r|r|r|r|r|r|r|r|}
\hline \multirow{2}{*}{ First Plant \& Machinery } & \multicolumn{9}{|c|}{ Latest Plant \& Machinery } \\
\cline { 2 - 13 } & I & \multicolumn{1}{|c|}{ II } & III & IV & V & VI & VII & VIII & IX & Total \\
\hline 1. CNC & 0 & 13 & 0 & 0 & 0 & 0 & 0 & 0 & 0 & 13 \\
\hline 2. Conventional lathe & 0 & 26 & 5 & 1 & 0 & 0 & 1 & 0 & 0 & 33 \\
\hline 3. Drilling & 0 & 0 & 0 & 1 & 1 & 0 & 0 & 0 & 0 & 2 \\
\hline 4. Gear hobbing & 0 & 0 & 0 & 0 & 0 & 1 & 0 & 0 & 0 & 1 \\
\hline 5. Grinding \& milling & 0 & 5 & 0 & 0 & 0 & 0 & 0 & 0 & 0 & 5 \\
\hline 6. Hand pressers & 0 & 1 & 0 & 0 & 0 & 0 & 0 & 0 & 0 & 1 \\
\hline 7. Horizontal boring & 0 & 1 & 0 & 0 & 1 & 0 & 0 & 0 & 0 & 2 \\
\hline 8. Hydraulic press & 1 & 0 & 0 & 0 & 0 & 0 & 0 & 0 & 0 & 1 \\
\hline 9. Injection molding & 0 & 1 & 0 & 0 & 0 & 0 & 0 & 0 & 0 & 1 \\
\hline 10. Milling & 0 & 1 & 0 & 0 & 0 & 0 & 0 & 0 & 0 & 1 \\
\hline 11. Power press & 0 & 1 & 0 & 0 & 0 & 0 & 0 & 0 & 0 & 1 \\
\hline 12. Punching & 0 & 1 & 0 & 0 & 0 & 0 & 0 & 0 & 0 & 1 \\
\hline 13. SS automats & 0 & 1 & 0 & 0 & 0 & 0 & 0 & 1 & 0 & 2 \\
\hline 14. TIG wielding & 0 & 0 & 0 & 0 & 0 & 0 & 0 & 0 & 1 & 1 \\
\hline 15. Tool room milling & 0 & 1 & 0 & 0 & 0 & 0 & 0 & 0 & 0 & 1 \\
\hline 16. Turning centre & 0 & 1 & 0 & 0 & 0 & 0 & 0 & 0 & 0 & 1 \\
\hline 17. Vertical machining centre & 0 & 1 & 0 & 0 & 0 & 0 & 0 & 0 & 0 & 1 \\
\hline \multicolumn{1}{c}{ Total } & 1 & 54 & 5 & 2 & 2 & 1 & 1 & 1 & 1 & 68 \\
\hline
\end{tabular}

Note: I. Automation; II. CNC; III. Conventional lathe; IV. Electrical Discharge Machining (EDM); V. Drilling; VI. Gear hobbing; VII. Special purpose machine (SPM); VIII. SS Automats; IX. TIG welding, Shearing and Bending machine.

Further all these SMEs have acquired technologies directly from technology suppliers, without the involvement of any SME supporting agency. (Of course, a significant number of them have obtained financial support from either KSFC or SIDBI or SBI). Some of them had informal consultations with some engineering Professors of academic institutions, particularly Indian Institute of Science, Bangalore. Accessing technical journals, Internet based technology information search, visiting machine manufacturers exhibition in Bangalore as well as New Delhi, interacting with the officials of Technology Resource Centre, Bangalore as well as with the members of SME associations are all done periodically. However their explicit role in ETAs is hardly referred.

It is important to note here that the role of government promoted agencies such as TRCs, KCTU, CMTI, etc. is largely absent. This is because formal network comprising government promoted agencies involves bureaucratic procedures leading to delays and sometimes, even an increase in the cost of ETA. Further, because majority of these SMEs had technically qualified 
CEOs who had "knowledge about the sources of better technology" with respect to "well-developed CNC technology" and "how to procure it", they did not find it worthwhile to approach any government promoted agency. This brings out that Bangalore SMEs did not seek external assistance for ETAs, mainly for two reasons: (i) dealing with government bureaucracy is time-consuming and therefore can be expensive, and (ii) CEOs are technically qualified and therefore capable of acquiring sufficient knowledge on their own, on the sources of technology and how to procure it, and (iii) $\mathrm{CNC}$ technology is well-developed and widely accepted in the industry.

Given this, the next important issue is did they source their technology from India or abroad? The source of technology (plant \& machinery) can be described in terms of countries in which the plant \& machinery is made, irrespective of where it is bought. The classification of machineries bought by SMEs is made in terms of country of origin (where the machinery is manufactured) and is presented in Table 2. At the time of origin, 51 of the 68 SMEs $(75 \%)$ procured Indian made technologies and the rest bought from abroad. But as of 2011, only 31 of the 68 SMEs (about 46\%) continued to have Indian made technologies and one SME which had a German made technology shifted to an Indian made technology. Twenty of the 51 SMEs (about $30 \%$ of the total) which had Indian made technologies shifted to technologies obtained from different foreign countries such as China, Germany, Hungary, Japan, Taiwan, Thailand, and USA. Overall, as of 2011, 36 SMEs (about 53\%) had foreign made technologies.

The major shift from Indian to foreign made $\mathrm{CNC}$ machines can be reasoned out as follows: We have learnt that Bangalore has a considerable presence of $\mathrm{CNC}$ technology suppliers/dealers, apart from $\mathrm{CNC}$ machine manufacturers. There are five $\mathrm{CNC}$ machine manufacturers in Bangalore, namely, (i) ACE designers, (ii) Bharath Fritz Werner (BFW), (iii) Hindustan Machine Tools (HMT), (iv) Liebherr - machine tools, and (v) Makino India. Of these, the first two are Indian private companies, the third one is an Indian Public Sector Company, and the fourth one is a joint venture involving an $\mathrm{MNC}$ whereas the fifth one is a fully-owned subsidiary of a MNC. Thus there are only three Indian CNC manufacturers located in Bangalore. In addition, there are about $25 \mathrm{CNC}$ machine dealers/suppliers located in Bangalore, most of whom supply CNC machines manufactured in different foreign countries such as Germany, Japan, Korea, China, UK, USA, etc. This brings out that 
buying a foreign-made CNC machine is as easy as buying an Indian-made or India made CNC machine in Bangalore for the machinery SMEs.

Another important reason for the shift (which facilitated the emergence of foreign technology dealers in Bangalore) can be attributed to the removal of constraints on foreign technology imports since 1991 (Bala Subrahmanya, 2004). Prior to 1991 India had restrictions on foreign technology imports and there were hardly any foreign technology dealer located in Bangalore. With the introduction of economic liberalization and removal of restrictions on foreign technology imports, gradually foreign technology dealers emerged in Bangalore enabling the local SMEs to procure foreign technologies locally. Further, foreign made technologies have always had an appeal to Indian SMEs on the grounds of high-quality and efficiency. Particularly, like elsewhere in the global market, German and Japanese machines have a high reputation for their "high-quality and higher efficiency" in India. Thus three factors would have facilitated the shift of Bangalore SMEs from Indian made technologies to foreign-made technologies: (i) Policy driven, (ii) Perception driven, and (iii) Supply driven.

Table 2 Sources of technology (SoT)

\begin{tabular}{|c|r|r|r|r|r|r|r|}
\hline \multirow{2}{*}{$\begin{array}{c}\text { SoT- } \\
\text { Current }\end{array}$} & \multicolumn{7}{|c|}{ SoT - Origin } \\
\cline { 2 - 8 } India & Germany & Japan & Taiwan & \multicolumn{1}{c|}{ UK } & \multicolumn{1}{c|}{ USA } & Total \\
\hline India & 31 & 1 & 0 & 0 & 0 & 0 & 32 \\
\hline China & 1 & 0 & 0 & 0 & 0 & 0 & 1 \\
\hline Germany & 7 & 4 & 0 & 0 & 0 & 2 & 13 \\
\hline Hungary & 1 & 0 & 0 & 0 & 0 & 0 & 1 \\
\hline Japan & 5 & 2 & 3 & 0 & 0 & 0 & 10 \\
\hline Korea & 0 & 0 & 0 & 1 & 0 & 0 & 1 \\
\hline Switzerland & 0 & 1 & 0 & 0 & 0 & 0 & 1 \\
\hline Taiwan & 1 & 0 & 0 & 0 & 0 & 0 & 1 \\
\hline Thailand & 3 & 0 & 0 & 0 & 0 & 0 & 3 \\
\hline UK & 0 & 0 & 0 & 0 & 1 & 0 & 1 \\
\hline USA & 2 & 0 & 1 & 0 & 0 & 1 & 4 \\
\hline Sum & 51 & 8 & 4 & 1 & 1 & 3 & 68 \\
\hline
\end{tabular}

In general, SMEs may decide to go for external technology acquisition for a variety of reasons such as, when the existing technology wears out or when they realize that competitors have gone for it or when their customers demand better quality products, or when they need to penetrate international markets, etc. We had an open ended question asking the respondents what prompted 
them to go for ETAs and the tabulated answers are given in Table 3. It is to acquire better quality and increase the scale of production that majority SMEs (about 2/3) have gone for ETAs followed by those who wanted to satisfy costumers' demand. Market expansion, faster delivery \& reduced lead time, acquiring competitive advantage, better accuracy, to depend less on skilled labour and to replace outdated machinery that other SMEs have gone for ETAs. Many SMEs had more than one objective to go for ETAs. Overall, it is important to note that SMEs are responsive to their external environment, and technological obsolescence is not the most important factor prompting them to go for ETAs. As stated by many of them, it is the liberalization of technology imports which has enabled them to procure external technologies as and when they need, particularly foreign technologies.

Table 3 Objectives of ETA

\begin{tabular}{|l|c|}
\hline \multicolumn{1}{|c|}{ Factors } & No of SMEs \\
\hline 1. Better quality and increased output & 45 \\
\hline 2. Fulfill customers demand & 37 \\
\hline 3. For market expansion & 23 \\
\hline 4. Faster delivery and reduced lead time & 11 \\
\hline 5. For competitive advantage & 9 \\
\hline 6. Constant accuracy/repeatability/reduced rejection & 7 \\
\hline 7. Less dependence on skilled manpower & 4 \\
\hline 8. To replace outdated machinery & 3 \\
\hline Total & 139 \\
\hline
\end{tabular}

Note: Many SMEs had multiple objectives in going for ETA.

Considering the well-known perception that Indian SMEs are in general known for technological obsolescence (Bala Subrahmanya, 2004), one would anticipate 'overcoming technological obsolescence' to be the most important factor prompting SMEs to go for ETAs. But in contrary, market/competition related factors have prompted them to go for ETAs. Given the change in market environment in the country subsequent to the initiation of economic liberalization in 1991, [characterized by industrial de-licensing, removal of restrictions on foreign direct investment and foreign technology imports, among others, (Bala Subrahmanya, 2004)] Bangalore SMEs would have focused on achieving 'market competitiveness' through supplementing their plant \& machinery with more advanced CNC machines, without waiting for their technology to become obsolete. As a result, market factors appear as 
more prominent influential objectives for the ETAs of Bangalore SMEs. This inference is further substantiated when we looked at the time taken by these SMEs for their first ETA.

Thus, how much time did these SMEs take for their first ETA after establishment is the other important issue? Figure 1 reveals that in general SMEs go for their first ETA in their earlier years after establishment than later. While three of them started their operations by acquiring external technologies, as many as 19 of the 68 SMEs (accounting for almost 28\%) opted for their first ETA within two years of their establishment. Another 13 SMEs (about 19\%) went for the first ETA after two years but within four years of their establishment. Another 7 SMEs went for ETAs after 4 four years but within six years of their inception. Thus a total of 39 SMEs (>57\%) (excluding those three which started with ETAs) have gone for ETA within the first six years of their establishment. This brings out that Bangalore SMEs did not wait for their technology to become obsolete when they went for their first ETA, rather they acquired their first external technology much before the exhaustion of full-life of their initial plant \& machinery, in response to market developments.

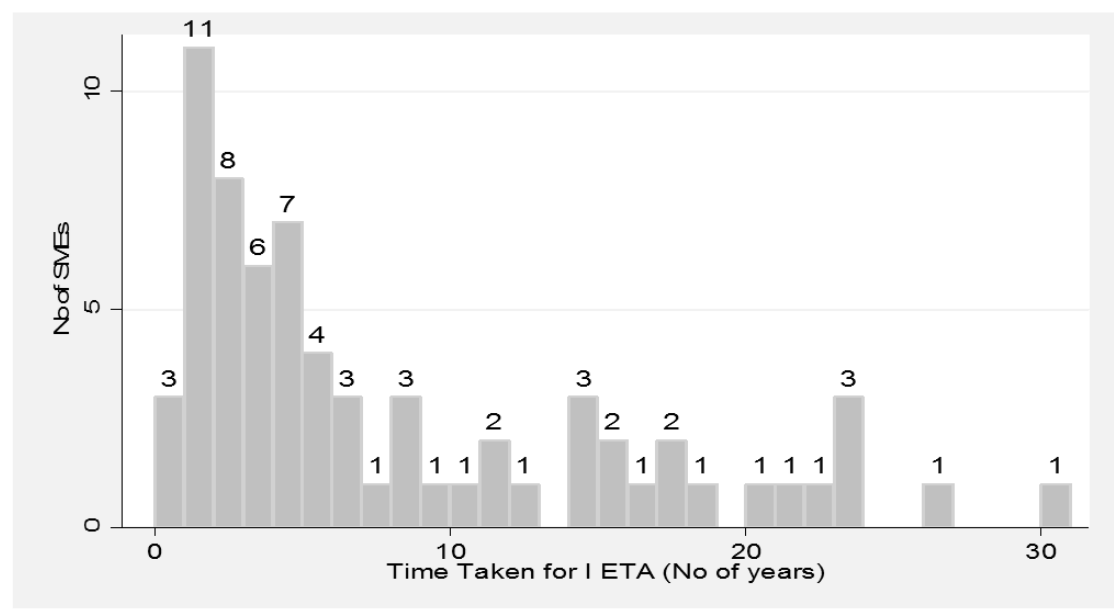

Figure 1 Time Taken for the First ETA 
The number of SMEs which went for ETAs is considerably less for later years. This implies that SMEs have preferred to go for ETA sooner in their life for improving their competitiveness for survival and growth rather than in later years. This is understandable because entrepreneurship literature reveals that initial years of their life are much more crucial for their survival and growth than later years. This is because internationally, it has been observed (Stokes, 1995) that:

- The young are more likely to die than the old: $10 \%$ to $15 \%$ of new ventures survive less than one year, and a third die within three years.

Perhaps majority Bangalore machinery SMEs are resorting to ETAs primarily as a means of their "competitive strategy", among others.

Table 4 presents the distribution of SMEs in terms of number of ETAs achieved by them. Majority SMEs (>96\%) have gone for more than one ETA since inception. This is understandable given the fact that most (3/4) of these SMEs are more than 10 years old; nearly $40 \%$ of the total are more than 20 years old. About $10 \%$ of the total SMEs have gone for ETAs for a minimum of seven times since inception. This brings out that the chosen SMEs have a fairly good experience of performing repeated ETAs. The age of SMEs and the number of ETAs achieved by them have a statistically significant positive correlation (+0.40) implying that older firms would have gone for more ETAs than the younger ones. It is equally important to know how much time is required for SMEs to accomplish an ETA. We looked at their first ETA as well as their latest ETA. The data are presented in Table 5.

Table 4 No of ETAs

\begin{tabular}{|c|c|c|}
\hline No of ETAs & No of SMEs & $\%$ \\
\hline 1 & 3 & 4.41 \\
\hline 2 & 10 & 14.71 \\
\hline 3 & 12 & 17.65 \\
\hline 4 & 21 & 30.88 \\
\hline 5 & 10 & 14.71 \\
\hline 6 & 4 & 5.88 \\
\hline 7 & 1 & 1.47 \\
\hline 8 & 6 & 8.82 \\
\hline 10 & 1 & 1.47 \\
\hline Total & 68 & 100.00 \\
\hline
\end{tabular}


Table 5 presents a two-way table showing how the time required to achieve the process of ETAs has changed from the first ETA to the latest ETA of 68 SMEs. While the time taken for the first ETA varied from one month to eight months, the time required for the latest ETA varied from one month to six months. Further, for the first ETA, 39 of the 68 SMEs (about $57 \%$ ) took three or less months and the remaining 29 SMEs took more than three months and up to eight months. Whereas for the latest ETA, 42 SMEs (almost 62\%) took three or less months and the remaining 26 SMEs took more than three months but not more than six months. Thus there appears a reduction in the time taken by SMEs for achieving their latest ETAs compared to their first ETAs.

Table 5 Time taken for the process of completing ETA

\begin{tabular}{|c|c|c|c|c|c|c|c|}
\hline $\begin{array}{c}\text { Duration for } \\
\text { the first ETA }\end{array}$ & \multicolumn{6}{|c|}{ Duration for the latest ETA (in months) } & \multirow{2}{*}{$\begin{array}{c}\text { Total } \\
\text { SMEs }\end{array}$} \\
\cline { 2 - 7 } (in months) & I & II & III & IV & V & VI & \\
\hline 1 & 3 & 0 & 0 & 0 & 0 & 0 & 3 \\
\hline 2 & 0 & 11 & 3 & 1 & 0 & 1 & 16 \\
\hline 3 & 2 & 3 & 14 & 1 & 0 & 0 & 20 \\
\hline 4 & 0 & 0 & 1 & 11 & 0 & 0 & 12 \\
\hline 5 & 0 & 1 & 1 & 0 & 2 & 0 & 4 \\
\hline 6 & 1 & 0 & 2 & 2 & 1 & 6 & 12 \\
\hline 8 & 0 & 0 & 0 & 0 & 0 & 1 & 1 \\
\hline Total SMEs & 6 & 15 & 21 & 15 & 3 & 8 & 68 \\
\hline
\end{tabular}

To ascertain whether the reduction in the average time taken for accomplishing ETAs over a period of time, from the first ETAs to the latest ETAs, has any statistical significance, we carried out a t-test comparing the two groups. Group 1: Number of months taken by each of 68 SMEs for their first ETAs, and Group 2: Number of months taken by each of 68 SMEs for their latest ETAs. The $t$ test results are presented in Table 6 . The average time taken for achieving ETAs has reduced over a period of time, for the latest ETA compared to the first ETA from 3.57 months to 3.26 months. Further the difference between the two groups for the average time taken for achieving ETAs is statistically significant. 
Table 6 Two-sample t-test results

\begin{tabular}{|c|c|c|c|c|}
\hline Variable & $\begin{array}{c}\text { No of } \\
\text { Observations }\end{array}$ & Mean & $\begin{array}{c}\text { Standard } \\
\text { Error }\end{array}$ & $\begin{array}{c}\text { Standard } \\
\text { Deviation }\end{array}$ \\
\hline First ETA & 68 & 3.57 & 0.19 & 1.57 \\
\hline Latest ETA & 68 & 3.26 & 0.17 & 1.41 \\
\hline Combined & 136 & 3.41 & 0.12 & 1.49 \\
\hline Difference & \multicolumn{4}{|c|}{ Degrees of freedom $=134$} \\
\hline \multicolumn{5}{|c|}{$\mathrm{t}=1.2038$ (Significant at 0.05 level) } \\
\hline
\end{tabular}

The statistically significant reduction in the time taken for the latest ETA compared to the first ETA (though marginal) may be attributed to several factors: (i) The repeated ETAs could have enabled the SMEs to learn the ETA process, over a period of time, (ii) The 'easy availability' of CNC technology locally due to the increase in the number of CNC technology dealers/suppliers in Bangalore city and the competition among them, and (iii) The quick information diffusion relating to $\mathrm{CNC}$ technologies within Bangalore SMEs due to the spread of ICT network in India in general and Bangalore, in particular. Of these, the first factor assumes significance and calls for further examination.

If SMEs have achieved latest ETAs in a lesser period of time compared to their first ETAs, this could be because they would have learnt the process of ETAs and it would be possible to map the ETA process. It is important to examine the process of ETAs adopted by SMEs. Achieving ETAs is not a simple affair. It involves entrepreneurial efforts, takes time and costs money and finally it should lead to the achievement of desired objectives. Therefore, it is appropriate to ascertain the important phases in ETAs for developing a systematic approach for planning and managing ETAs.

A qualitative discussion with the founder entrepreneurs of all the SMEs enabled us to understand that there is a broad pattern in the process of ETAs achieved over a period of time. It is the realization for a better technology (Technology Need) triggered by either customer demand or availability of better products (in terms of quality and cost) from competitors or both which initiates the search for technology alternatives (Technology Search). Merits and de-merits of internal technology development versus external technology acquisition are examined. Often, because acquiring technology from outside appears more economical, SMEs generally prefer to go for ETAs. Once the 
decision for ETA is made, then different options available for ETAs are examined to decide on a particular channel (Technology Identification).

After the decision to acquire a particular technology from a particular channel is made, a pre-feasibility study is conducted. This is followed by adequate training of labour (Technology Assessment). Once an order is placed and new technology is obtained, it is installed followed by trial runs. This would involve improvements in the firm infrastructure as desired by the new technology. Based on satisfactory performance, new technology based manufacturing starts, which completes the process of ETA (technology acquisition and absorption). Thus, broadly, there are 5 stages involving 11 steps in the process of ETAs and are represented in Figure 2.

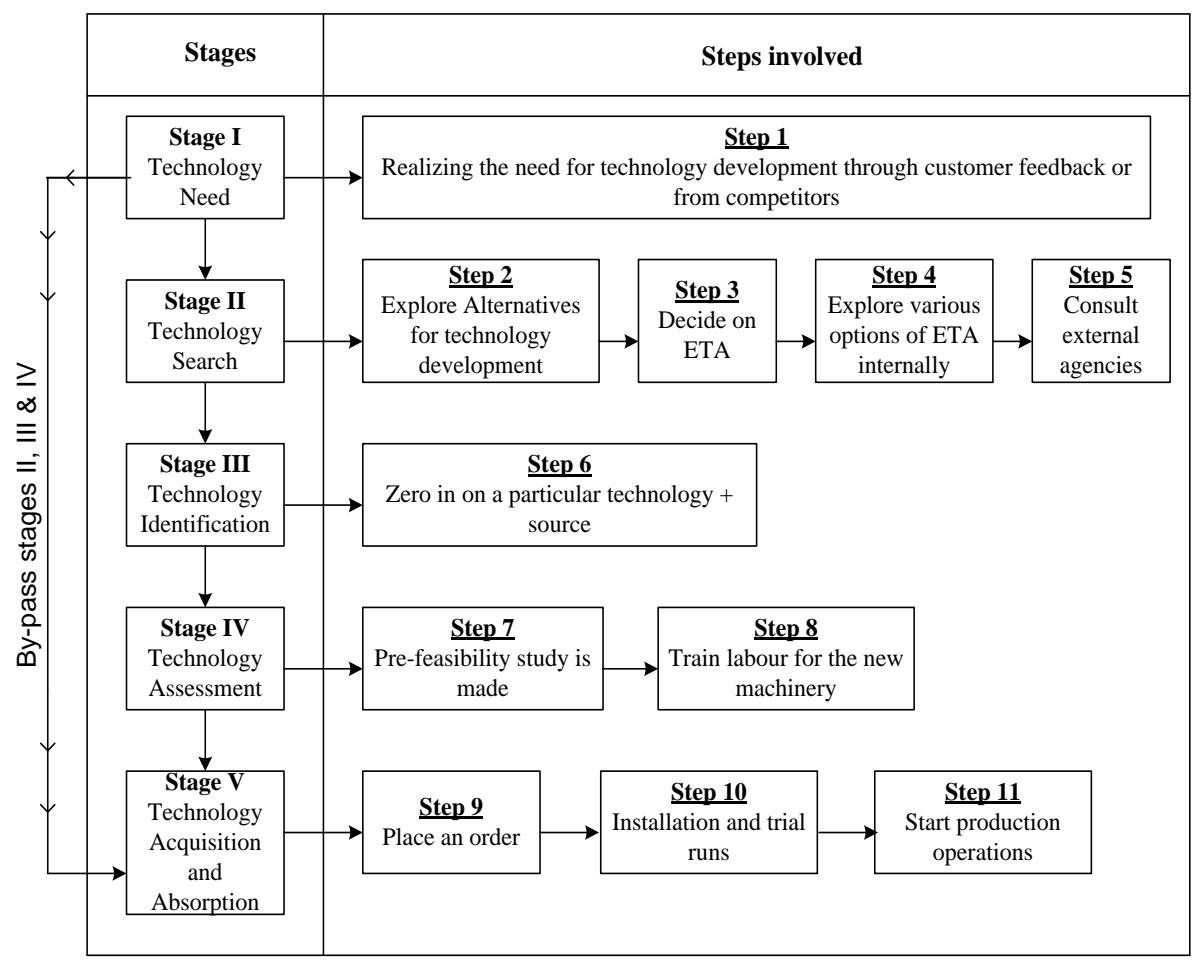

Figure 2 Stages and steps involved in ETA 
This broad pattern is observed in most of the 68 SMEs and has been confirmed by many of them. In fact, after mapping the process of ETAs, we again visited five of these SMEs personally, and interacted with the founder entrepreneurs. All of them agreed with the proposed mapping. Thus ETAs in SMEs can be looked at from a process perspective consisting of five major stages and 11 steps. The major advantage of identifying such a broad pattern of ETAs consisting of stages and steps based on the experience of SMEs is that it can be used as a guideline for a SME which approaches the task of ETA without any prior experience, to be more task-oriented and save on time, efforts and cost. This will particularly benefit those SME CEOs who are not technically qualified but have the zeal to do business.

\section{Inferences and Conclusions}

The machinery SMEs in Bangalore are all start-ups and were founded by first-generation entrepreneurs, most of whom are technically qualified. They are either proprietorship or partnership concerns, primarily machine component manufacturers and have ICT networks. Majority SMEs have gone for acquiring $\mathrm{CNC}$ machines and therefore have adopted CAD/CAM programmes. Such SMEs would have also strengthened their software capability to enable the appropriate adaptation of the new technologies. There has been a significant shift towards ETAs from Indian to foreign made machines, particularly German and Japanese machines, among others. However irrespective of whether they have obtained the new technology from India or abroad, all of them have procured it directly from technology suppliers and none from any other channel. These SMEs had multiple objectives in going for ETAs. The primary objective of ETAs is to enhance their competitiveness by means of improving product quality and productivity as well as meeting customer demand. Faster delivery by reducing the lead time and achieving constant accuracy and reduced rejections are the other noteworthy objectives. Replacing outdated machinery or overcoming technological obsolescence is a primary objective of only a few.

Due to the above reasons, majority SMEs have gone for their first ETA in the initial couple of years rather than in the later years. Further majority 
SMEs have gone for multiple ETAs since their inception and we found a statistically significant positive correlation between firm age and number of ETAs. The time taken for the first ETA by these SMEs ranged from one month to 8 months whereas for the latest ETA, it ranged from one month to six months. On average, the 68 SMEs took 3.57 months for the first ETA whereas 3.26 months for the latest ETA indicating that the average time taken for ETAs has come down over the period. A t-test analysis brought out that the difference between the two groups for average time taken for achieving ETAs is statistically significant. This could be attributed to the "learning of ETAs" by SMEs, apart from other factors such as increased number of technology suppliers in Bangalore and competition among them.

If SMEs have learnt the art of ETAs and therefore could save on time and possibly on cost and efforts, they would have understood the pattern of ETAs. Our interactions with the SME entrepreneurs enabled us to develop a map of ETA comprising five stages involving 11 steps. The initial trigger is the realization for the need to have a better technology which leads to the subsequent stages and steps. Technology need leads to Technology search, which results in Technology identification. Once a technology is identified, an intensive Technology assessment is made followed by Technology acquisition and absorption. However, experienced and/or technically qualified entrepreneurs with "vital information networks", virtually skip the intermediate stages and go for technology acquisition and absorption once the technology need is realized. In addition, this skipping is facilitated by the fairly "well-developed" $\mathrm{CNC}$ technology and the "widely available" technology dealer/supplier network for it. This again brings out the point that it is not learning alone which has enabled a reduction in the time taken for subsequent ETAs, but equally importantly it could be due to the welldeveloped CNC technology and widely available technology supplier network in Bangalore.

The present study has made two empirical contributions in the context of a "technology hub" in India. They are as follows: (i) We have thrown light on the core technology up-gradation issue - How do SMEs approach the problem of external technology acquisition in the current globalization era? This assumes significance because there has been considerable industrial policy liberalization in India since 1991, in terms of easing of controls and regulations on technology imports. As a result, SMEs are able to acquire 
external technologies with much ease, especially foreign made technologies directly from locally based suppliers. In the process, they are able to respond to "external signals and pressure" to sustain/improve their competitiveness by means of ETAs. Technological obsolescence is rather the least important reason for ETAs.

Thus ETAs of Bangalore based SMEs are encouraged by (a) Policy driven, (b) Perception driven and (c) Supply driven factors in the present competitive era. This brings out that when technology market is well matured and diffused and is available locally through agents/suppliers, SMEs even in an emerging economy will be able to adopt better technologies without the support of external agencies, as and when required/compelled by market forces. (ii) We are able to identify and develop a map of ETA process based on the "learning and experiences" of these SMEs. This mapping of ETA process can be a "guide" for new SMEs, particularly those which lack adequate internal technical strength and prior experience in dealing with technologies. This assumes significance because even now nearly $1 / 5$ of the SME CEOs are non-technically qualified in a tech-hub like Bangalore.

Finally, if Bangalore SMEs are "smart enough" to respond to policy changes and supply driven factors, and learn the process of ETAs effectively, the "smarter ones" among these, might keep another step forward in the future by "innovating" the acquired technologies for "better performance and growth" by taking advantage of the "high-tech ecosystem" prevailing in the city.

\section{Acknowledgement}

This paper forms part of the research project report titled, "External Technology Acquisition in Small \& Medium Enterprises: Experience and Efficacy", sponsored by Indian Council of Social Science Research (ICSSR), Government of India, New Delhi. The authors are grateful to the valuable comments and suggestions of three anonymous reviewers which greatly helped them to revise the paper. They are equally grateful to the Editor-inchief, Professor Sung-Soo Seol for his support and encouragement. However the views and analysis of the paper are authors own and they alone are responsible for any of the errors, if remain. 


\section{References}

Bala Subrahmanya, M.H. (2005a) Technological innovations in small enterprises: a comparative perspective of Bangalore (India) and Northeast England (UK), Technovation, 25, 269-280.

Bala Subrahmanya, M.H. (2005b) Technological innovations in Indian engineering industry: industry and firm level case studies, International Journal of Entrepreneurship and Innovation Management, 5(5/6), 401-420.

Bala Subrahmanya, M.H. (2004) Small industry and globalization: implications, performance and prospects, Economic and Political Weekly, 34(18), 1826-1834.

Bala Subrahmanya, M.H, Mathirajan, M., Balachandra, P., Srinivasan, M.N. and Laxman P. (2002) R\&D and Technological Innovations in Small Scale Industries, Allied Publishers Private Limited, New Delhi.

Bischoff, J. (2001) Technology Transfer, in Technology for Small Scale Industries: Current Status and Emerging Needs, Small Industries Development Bank of India, Lucknow, 109-133.

Daim, T.U. and Kacaoglu, D.F. (2008) Exploring technology acquisition in Oregon, Turkey and in the US electronics manufacturing companies, Journal of High Technology Management Research, 19, 45-58.

Department of Industries and Commerce (2012) Bengaluru, the political capital of Karnataka and knowledge capital of India, http://www.karnatakaindustry.gov.in/ bengaluru.html

Department of Science \& Technology (2010) Directory of R\&D Institutions 2010, Government of India, New Delhi.

KASSIA (2012) Association affliated to KASSIA, http://www.onlinebangalore.com/ indu/kasia.html.

Koc, T. and Ceylan, C. (2007) Factors impacting the innovative capacity in largescale companies, Technovation, 27, 105-114.

Lanctot, K. and Swan, K.C. (2000) Technology acquisition strategy in an internationally competitive environment, Journal of International Management, 6, 187-215.

Ministry of Micro, Small \& Medium Enterprises (MSMEs) (2012a) Report of the Working Group on MSMEs Growth for $12^{\text {th }}$ Five Year Plan (2012-2017), Government of India, New Delhi.

Ministry of Micro, Small \& Medium Enterprises (MSMEs) (2012b) Annual Report 2011-12, Government of India, New Delhi.

Noori. H. (1990) Managing the Dynamics of New Technology, Prentice Hall, New Jersey.

Robertson, N. (1993) Technology acquisition for corporate growth, Research Technology Management, 36, 26-30.

Rogers, E.M., Takegami, S. and Yin, J. (2001) Lessons learned about technology transfer, Technovation, 21, 253-261.

Stock, G.N. and Tatikonda, M.V. (2004) External technology integration in product and process development, International Journal of Operations \& Production Management, 24, 642-665. 
Stokes, D. (1995) Small Business Management, DP Publications Ltd, London.

Tsai, K.H. and Wang, J.C. (2008) External technology acquisition and firm performance: a longitudinal study, Journal of Business Venturing, 23, 91-112.

UNDP (2001) Human Development Report 2001, Oxford University Press, New York.

Zahra, S.A., Sisodia, R. and Das, S. (1994) Domestic and international competitive focus, technology strategy and company performance: an empirical analysis, International Journal of Technology Management, 9, 172-195. 